G. Wolandt - Philosophie der Dichtung

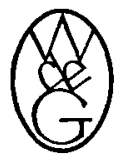





\title{
Gerd Wolandt
}

\section{Philosophie der Dichtung}

\author{
Weltstellung und Gegenständlichkeit \\ des poetischen Gedankens
}

\section{Walter de Gruyter \& Co - Berlin 30}

Vormals G. J. Göschen'sche Verlagshandlung · J.Guttentag, Verlagsbuchhandlung Georg Reimer - Karl J. Trübner - Veit \& Comp. 


\section{Archiv-Nr. 3637651}

\section{(c)}

1965 by Walter de Gruyter \& Co., vormals G. J. Göschen'sche Verlagshandlung - J. Guttentag, Verlagsbudhandlung - Georg Reimer - Karl J. Trübner - Veit \& Comp., Berlin 30, Genthiner Str. 13. Printed in Germany.

Alle Rechte, insbesondere das der Ubersetzung in fremde Sprachen, vorbehalten. Ohne ausdrückliche Genehmigung des Verlages ist es auch nicht gestattet, dieses Buch oder Teile daraus auf photomechanischem Wege (Photokopie, Mikrokopie, Xerokopie) zu vervielfältigen.

Satz und Drudk: Thormann \& Goetsch, Berlin 44. 